\title{
O uso de habilidades comunicativas verbais para aumento da extensão de enunciados no autismo de alto funcionamento e na síndrome de Asperger***
}

\author{
The use of verbal communicative abilities to increase the mean \\ length of utterance in high-functioning autism and Asperger \\ Syndrome
}

Simone Aparecida Lopes-Herrera*

Maria Amélia Almeida**

*Fonoaudióloga. Doutora em Educação Especial pela Universidade Federal de São Carlos. Docente do Departamento de Fonoaudiologia da Faculdade de Odontologia de Bauru da Universidade de São Paulo. Endereço para correspondência: Al. Doutor Octávio Pinheiro Brisolla, 9-75 Bauru - SP CEP: 17012-101

(lopesimone@usp.br).

**Educadora. PhD em Educação Especial pela Vanderbilt University. Coordenadora do Programa de PósGraduação em Educação Especial da Universidade Federal de São Carlos.

***Trabalho Realizado na Universidade Federal de São Carlos Programa de Pós-Graduação em Educação Especial.

Artigo Original de Pesquisa

Artigo Submetido a Avaliação por Pares

Conflito de Interesse: não

Recebido em 19.10.2006

Revisado em 24.07.2007; 15.08.2007; 01.02.2008.

Aceito para Publicação em 01.02.2008.

\section{Abstract}

Background: high-functioning autism (HFA) and Asperger Syndrome (AS) are pervasive developmental disorders that present alterations in the communicative and social skills. Aim: to use verbal communicative skill strategies (VCS) to increase the mean length of utterance (MLU) produced by individuals with HFA and AS. Method: participants were three 12-year-old males with HFA or AS. Data was collected from videotape recordings of structured verbal interaction sessions with the researcher and each participant during eight months. In order to verify the effects of the intervention, a multiple baseline research design across the participants was used, being composed by two phases: baseline (BL) and intervention (I). In the BL phase, spontaneous interaction situations occurred between the researcher and each participant. In the first phase of I, the intervention sessions occurred twice a week and gradually worked their way to once a week, but only after each participant had reached the goal of increasing the MLU. The number of sessions decreased gradually to avoid any drop in performance. The strategies which were used were divided in blocks of activities: spontaneous conversation; activities involving specific language difficulties; games with rules; story/report telling; and meta-linguistic activities. Results: the application of the proposed strategies for verbal communicative abilities achieved the purpose of increasing the MLU of all three participants. Conclusion: suggestions are made for further researches that investigate the maintenance of the results in other environments and during the interaction with different communication partners. Key Words: Autism; Asperger Syndrome; Language; Special Education.

\section{Resumo}

Tema: o autismo de alto funcionamento (AAF) e a síndrome de Asperger (SA) são transtornos globais do desenvolvimento que apresentam alterações nas habilidades comunicativas e sociais. Objetivo: o objetivo desta pesquisa foi promover o aumento da extensão média dos enunciados (EME) produzidos por indivíduos com AAF e SA por meio de estratégias que utilizavam habilidades comunicativas verbais (HCV). Método: participaram deste estudo três indivíduos com AAF ou SA do gênero masculino, com doze anos. Os dados foram coletados mediante gravações em vídeo de sessões estruturadas de interação verbal entre cada participante e a pesquisadora durante oito meses. Foi utilizado um delineamento experimental de linha de base múltipla cruzando com sujeitos, composto por duas fases: linha de base (LB) e intervenção (I). Na LB, ocorreram situações espontâneas de interação adulto e cada participante. Na primeira fase da I, inicialmente foram realizadas sessões duas vezes por semana e só se passava para a realização de sessões semanais após o indivíduo alcançar o objetivo de aumentar a EME. Houve a diminuição gradual do número de sessões, para que não houvesse queda no desempenho. As estratégias aplicadas foram divididas em blocos atividades com conversa espontânea; atividades que envolvessem dificuldades específicas de linguagem; jogos de regras; solicitações de relatos de histórias ou acontecimentos e atividades metalingüísticas. Resultados: os resultados demostraram que a utilização de HCV foi efetiva para promover o aumento da EME. Conclusão: ficam sugestões para outras pesquisas que investiguem a manutenção dos resultados obtidos em outros ambientes e em interação com vários interlocutores.

Palavras-Chave: Autismo; Síndrome de Asperger; Linguagem; Educação Especial. 


\section{Introduction}

Autism (A) and Asperger Syndrome (AS) are Pervasive Developmental Disorders (PDD). Their diagnosis are basically clinical, that is, it is carried through by means of behavioral observation analysis and analysis of individual history and not by means of laboratory examinations - with the exception of when autism appears associated to another condition (1).

The diagnosis of high functioning autism (HFA) is considered to individuals whom received the diagnostic before thirty months of age, whom have developed abilities of social interaction/ communication and that are not included in the criteria considered by the international diagnostic manuals for any other PDD or mental delay (2-5).

There is a substantial number of researches that identifies particular PDD characteristics regarding language alterations, being this area one of the main areas of intervention (6-8). One of the principles more widely accepted for intervention in language is to enable the individual to discover the rules and regularities of linguistic units, concepts and contexts that occur in the environment. Therefore, strategies that make possible the creation of natural situations, in order to enable the individual to observe peculiarities and adaptations that are made due to the communicative context are important for the verbal communicative ability performance (9-10).

This way, an intervention program with verbal communicative ability (VCA) in order to increase the mean length of utterances (guaranteeing its understanding) produced by individuals with HFA e AS is proposed in this research.

It is believed that when all the language aspects (content/form/use) are used in an intervention plan, a primary focus in one aspect may facilitate the development of other aspects in a concomitant manner for the individual.

Therefore, this research had the objective to promote the increasement of the mean length of utterances through therapeutic strategies that utilized VCA(10) in individuals diagnosed with HFA and AS.

\section{Methods}

All the procedures of this research were approved by the Research Ethics Committee of the Universidade Federal de Sao Carlos (UFSCar), under protocol $n^{\circ}$ 046/2002 (as Resolution 196/96 of the Brazil National Council of Health).

\section{Participants}

Three 12-year-old males diagnosed with AS (participant 1 - P1) or HFA (participants 2 and 3 - P2 and P3) participated in the study.

\section{Data collection procedures}

Video recording sessions of individual intervention through a period of 8 months were carried through. Each recording had the total duration of 30 minutes. The 20 central minutes were analyzed. At the end of the analysis 3,240 minutes of writings were counted.

Each session was transcribed and the data were transferred to a protocol with the description of the VCA of adults and participants and notation of the measures of analysis. It was defined, based on the literature (11-12), to adopt the minute to minute analysis and to adopt the following measures:

- verbal Production (number of verbal units per minute): verbal unit (or utterance) is defined as a set of words, delineated by inflection and respiratory pauses that corresponds to pauses demarcated by the conventional punctuation in writing. Example: "Ready? How do you want to play today?" - two verbal utterances;

. number of words per minute: vocalizations with more than one syllable that presented referred listings in dictionary or related in the same way by the immediate or specific community (family dictionary) were considered words. Productions of one syllable were considered words only when personal, relative and possessive pronouns, affirmative or negative adverbs, numerals and occasionally verbs (Example: the verb to be). Example: in the two previous utterances there were eight words;

. mean Length of Utterance (MLU): average of words over the total verbal units defined each minute (value calculated by dividing the total number of words by the number of utterances). Example: if there are eight words and two utterances produced, the MLU is four.

The design of multiple baseline across subjects was utilized in order to verify the effects of intervention. In this type of research design each participant is compared to himself, not having the necessity of statistical tests in data analysis. The accomplishment of this study was done in two phases: baseline (BL) and intervention (INT).

During the BL phase, sessions of spontaneous interaction between adult and each one of the participants occurred, in a frequency of two times per week. In the phase of BL, the adult only answered to the attempts of spontaneous interaction of the participants, supplying the as smaller as possible 
number and variation of VCA.

The intervention (INT) was constituted by structured sessions of interaction of the adult with each one of the participants. The final criterion of the INT was established in $100 \%$ of addition in the mean value of the MLU of the three last BL sessions. This way, the frequency of accomplishment of the sessions was twice a week until the establishment of the INT criterion (phase 1 of INT), weekly (phase 2 ), biweekly (phase 3 ) and monthly (phase 4). The care to the gradual reduction of the number of sessions was taken so that the results obtained in intervention phase were preserved.

The sessions of INT with P1 were carried through twice a week until the established criterion of INT was reached, while P2 and P3 were maintained in BL. When P1 had already reached $50 \%$ of increase in his MLU, the INT was initiated with P2, while the INT sessions with P1 had started to be weekly and P3 was maintained in BL. The same criterion was used to initiate INT with P3.

For the general organization of the sessions, the strategies were divided into blocks, in a manner to stimulate the participant to use the greatest possible number and variability of VCA.

In the first block (30\% of the sessions), the privileged strategy was the spontaneous conversation, in which the adult left of some specific interest of the participant, extending it with the use of specific VCA, such as asking for information (AI) or report/storytelling (RS), reproduction of stories (RPS), interpretation of stories (IS) and argument (ARG).

A second block of strategies (25\% of the sessions) used games and other activities that involved specific language difficulties in the HFA and the AS. Example of these being the attribution of double meanings and comprehension of noncontextual situations, failures of perception/ interest for the other, inability in the assimilation of social rules and other pragmatic alterations.

The third block of strategies ( $20 \%$ of the sessions) was elaborated in a manner to promote the clarity in the facts exposure, characteristics and arguments by means of games of rules.

The fourth block of strategies $(15 \%$ of the sessions) was consisted by the request of stories or events (report/storytelling ability - RS) debriefing in a direct form or from elements (figures or drawings).

The fifth and last block of strategies (10\% of the sessions) was composed by metalinguistic activities, as guessing and others that favored the use of VCA, such as comments (CM), asking for information (AI), direct responses (DR) and report/storytelling (RS).

The reliability index of this study varied between $91,81 \%$ and $94,42 \%$, having the evaluation inter observers been carried through in $40 \%$ of the sessions.

Data analyses procedure

After the fulfilling of the protocol, the data was transferred to a table in a manner that the measures were available in its total and average values, being evaluated in a quantitative and qualitative form.

\section{Results}

Figure 1 shows the results of the sessions of baseline (BL) and intervention (INT) with the three participants (P1, P2 and P3). It is observed that the performance curve of all participants was ascending, demonstrating that the INT presented the expected effect to increase the MLU. The P1 presented, at the beginning of the INT, a more ascending performance. The P2 took a smaller number of sessions to reach the established criterion as the final aim of INT (increase of $100 \%$ of the mean MLU obtained in the BL). The P3 necessitated a greater number of sessions to reach this objective.

Through Figure 1, it can be observed that - with the beginning of the INT - the performance of the P1 presented gradual and slow evolution, presenting plateaus between sessions 12 and 13. At this point, in session 15 , having already been reached the established criterion for phase 1 of the INT (value of MLU of at least 7,09), the INT passed to be carried through monthly. Therefore, the BL with P1 lasted 3 sessions, the first phase of the INT lasted 12 sessions and, totally, 31 sessions of INT were carried through.

For P2, in the beginning of the INT, the performance rise was observed until session 12 , with gradual and slow evolution until session 17 . At this point, there was a jump in its performance, having reached the established criterion for phase 1 of the INT (value of MLU of 7,07 at least) in session 19. Therefore, the BL with $\mathrm{P} 2$ had the duration of 9 sessions, the first phase of the INT had the duration of 10 sessions and, in total, 26 sessions of INT were carried through.

For P3, with the beginning of the INT, the performance showed a slight improvement, having this been gradual until session 19. From there, there was a slow evolution until the criterion established for phase 1 of the INT was reached in session 29 (value of MLU of at least 7,33). Therefore, the BL with P3 had duration of 12 sessions, the first phase of the INT was concluded in 18 sessions and, totally 28 sessions of INT were carried through.

When comparing the three curves, it is possible to see a trend of obtaining more quickly the result and maintenance of the gain in performance, in general, 
with the P1 - which is the individual with AS. It is important to highlight that this is not a comparative study, in a view of the fact of the small number of participants, although it has as base longitudinal recordings. The increase of the number of studies like this is suggested to verify whether the individuals with AS present more satisfactory performance when submitted to intervention procedures.

Regarding the use of VCA in BL and in INT, as it can be seen in table 1, that there was a quantitative jump in terms of VCA use by the participants. During the INT all of the VCA were used (with the exception of the SR ability - social routine) in varied degrees. It was presented a greater use of dialogue maintenance ability (DM), introduction of new topics (NT), comments (CM), direct responses (DR), directed attention (DAT), directed action (DA), asking for information (AI), report/storytelling (RS) and argument ability (ARG). The explanation to the non-appearance of social routine (SR) ability is in the fact that the data analysis disrespected the initial and final minutes of the sessions.

FIGURE 1. Values for average mean length of utterances (MLU) of participants 1 (P1), 2 (P2) and 3 (P3) in the baseline (BL) and intervention sessions (INT).

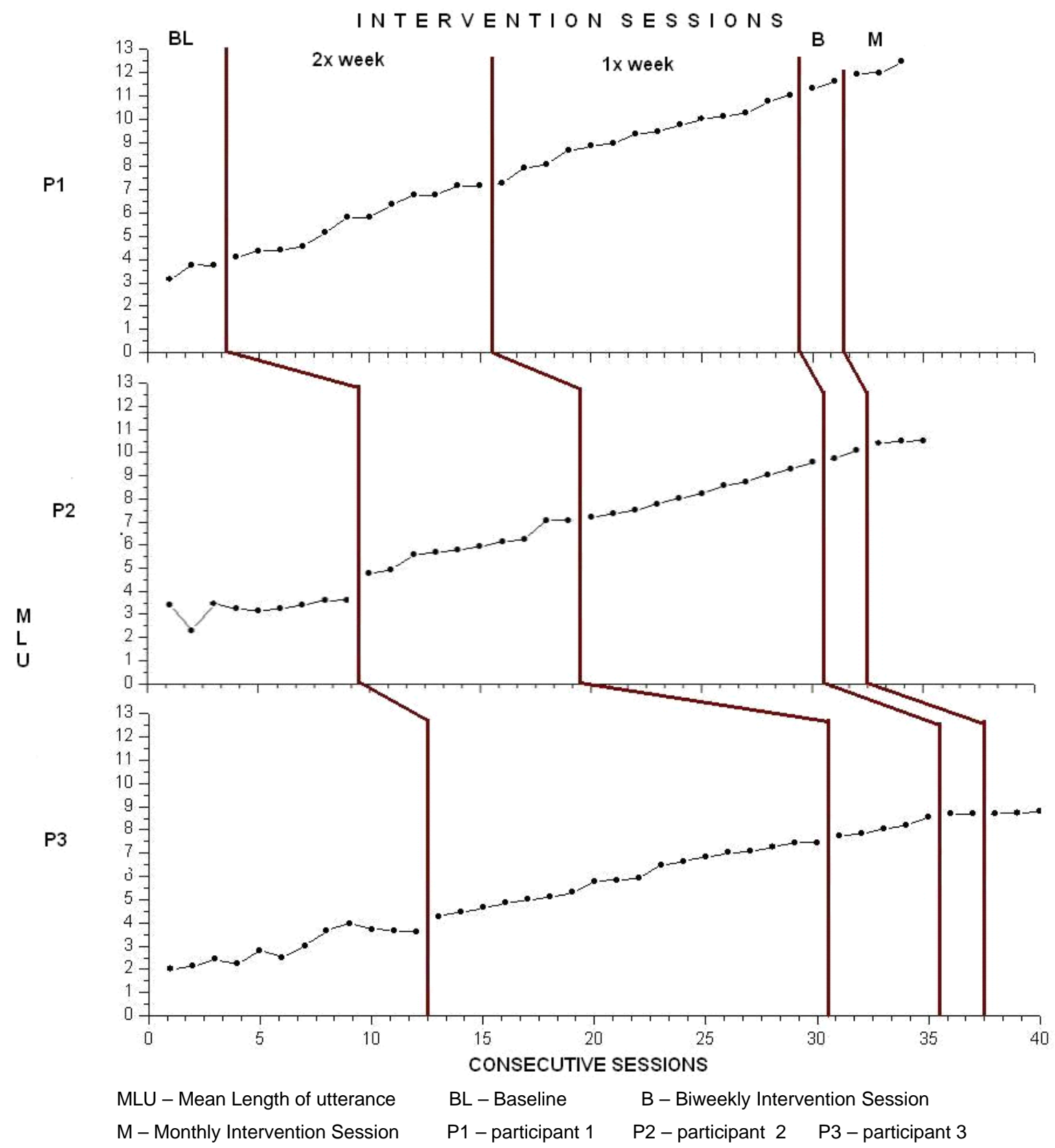


TABLE 1. Verbal communicative abilities (VCA) used by participants 1, 2 and 3 (P1, P2 and P3) in baseline sessions (BL) and in the total of intervention sessions (INT).

\begin{tabular}{|c|c|c|c|c|c|c|}
\hline VERBAL COMMUNICATIVE ABILITIES & & & & & & \\
\hline Dialogical Abilities (DA) & BL & INT & BL & INT & BL & INT \\
\hline Dialog Initiation - DI & & & & & & \\
\hline Dialog Maintenance - DM & & & & & & \\
\hline Introduction of New Topics - NT & & & & & & \\
\hline Sequential Organization/Dialog - SO (D) & & & & & & \\
\hline Comments - SO (CM) & & & & & & \\
\hline Direct Responses - SO (DR) & & & & & & \\
\hline Imitation - SO (I) & & & & & & \\
\hline Feedback to Interlocutor $-\mathrm{FI}$ & & & & & & \\
\hline Error Correction - EC & & & & & & \\
\hline Role-playing - RP & & & & & & \\
\hline Social Routine - SR & & & & & & \\
\hline Expression of Feelings - EF & & & & & & \\
\hline Control abilities (CA) & & & & & & \\
\hline Self-control - SC & & & & & & \\
\hline Directed Attention-DAT & & & & & & \\
\hline Directed Action - DA & & & & & & \\
\hline Asking for objects $-\mathrm{AO}$ & & & & & & \\
\hline Asking for Information - AI & & & & & & \\
\hline Permission $-\mathrm{P}$ & & & & & & \\
\hline Narrative-Discourse Abilities (NDA) & & & & & & \\
\hline Report/Storytelling - RS & & & & & & \\
\hline Reproduction of Stories - RPS & & & & & & \\
\hline Interpretation of Stories - IS & & & & & & \\
\hline Argument - ARG & & & & & & \\
\hline Non-interactive Skills & & & & & & \\
\hline Use of language to establish self identity- LI & & & & & & \\
\hline Symbolic Games - SG & & & & & & \\
\hline Metalanguage $-\mathrm{ML}$ & & & & & & \\
\hline
\end{tabular}

\section{Discussion}

The research and the clinical experience increase the understanding of the HFA and the AS and offer potential for perfectioning the therapeutic approaches. The transcription of language samples provides a clear description of the language that the individual uses and allows us to carry through the detailed analysis of its dimensions and processes. The spontaneous verbal production is the evaluation procedure that offers a more accurate description of the linguistic development level. Its stronger importance inhabits in the fact that once transcribed it allows a great variety of analyses (phonological, syntactic, semantics and pragmatic) and diminishes the risk of subjective interpretations or loss of information.

The difficulties involved in this type of research are the contextual dependence of the productions, the time expended in data collection, codification and analysis. However, among the advantages, such type of situation allows comparisons intraparticipants, what is seen as a positive fact by the behavioral and cognitive approaches.
The research presented here had as objective to promote the increase of the mean length of utterance by the use of strategies with verbal communicative abilities. The participants demonstrated a slow but constant evolution presenting - for times - some performance "jumps" and not having significant performance falls, showing an ascending curve, even when the intervention sessions had the frequency diminished.

In general, it is clear by the results displayed in this paper, the importance of a favorable and stimulator communicative environment as well as the importance of the programmed activities and structured situations. The most relevant finding is, without a doubt, the importance of the speaker to supply the individual with support for the communication. For this, it is necessary that the speaker is intent to all and any track and also to the specific interests and situations of daily life and natural environment (13). 
The emphasis on the fact of believing that individuals with HFAe AS do not present problems regarding the formal aspects of the language makes to be given, in research, emphasis on the evaluation of the functional aspects and not on the formal aspects. The formal aspects are also important in the communicative process (6). This way, the research on functional aspects falls, in its majority, in the evaluation of these deficits and not necessarily in their development (7-8). The research displayed here, although it has focused on the verbal communicative abilities (that includes the functional aspect), it proposed to develop a formal item of the language, that is the mean length of utterance.

\section{Conclusion}

This research reached the proposed objective, which was to increase the mean length of utterance of individuals with HFA and AS by means of

\section{References}

1. Machado MG, Oliveira HA, Cipolotti R, Santos CAGM, Oliveira EF, Donald RM, et al. Alterações anátomofuncionais do sistema nervoso central no transtorno autístico - um estudo com RNM e SPECT. Arquivos de Neuropsiquiatria. 2003;61(4):957-61.

2. Foster B, King BH. Asperger syndrome: to be or not to be? Current Opinion in Pediatrics. 2003;5:491-4.

3. Ghaziuddin M. A family history of Asperger syndrome. Journal of Autism and Developmental Disorders. 2005 Apr; 35(2):177-182.

4. Rutter M. Autism research: lessons from the past and prospects for the future. Journal of Autism and Developmental Disorders. 2005;35(2):241-57.

5. South M, Ozonoff S, Mcmahon WM. Repetitive behavior profiles in Asperger syndrome and high-functioning autism. Journal of Autism and Developmental Disorders. 2005; 35(2):145-58.

6. Ziatas K, Durkin K, Pratt C. Differences in assertive speech acts produced by children with autism, Asperger syndrome, specific language impairments and normal development. Development and Psychopathology. 2003;15(1):73-94.

7. Fernandes FDM. Resultados de terapia fonoaudiológica com adolescentes com diagnóstico inserido no espectro autístico. Pró-Fono Revista de Atualização Científica, 2005 Jan-Abr; 17(1):67-76. strategies with verbal communicative abilities. The results of this research contribute to the scientific development of the area, which necessitates each time more works that not only point the pragmatic characteristics or evaluate deficits of the individuals with HFA and AS. Researches that also propose to develop them, evaluating these individuals not in relation to the level of normal development or the level of the development of other individuals with the same pathology, but in relation to their proper level of previous performance are demanded.

We leave here suggestions so that other researches can be carried through in the search of development of new strategies or procedures that make possible an improvement of the verbal communicative ability of the individuals with pervasive developmental disorders. It is also suggested the reproduction of this study in populations of individuals with HFA or of individuals with AS itself and in other situations or communicative contexts with varied speakers (as the school and the familiar environment).
8. Cardoso C, Fernandes FDM. Relação entre os aspectos sócio cognitivos e perfil funcional da comunicação em um grupo de adolescentes do espectro autístico. Pró-Fono Revista de Atualização Científica. 2006 Jan-Abr;18(1):8998.

9. Klin A. Attributing social meaning to ambiguous visual stimuli in higher-functioning autism and Asperger syndrome: the social attribution task. Journal of Child Psychology and Psychiatry. 2000;7:831-46.

10. Lopes-Herrera SA. Avaliação de estratégias para desenvolver habilidades comunicativas verbais em indivíduos com autismo de alto funcionamento e síndrome de Asperger [tese de doutorado]. São Carlos (SP): Universidade Federal de São Carlos; 2004.

11. Brandão SA. O ambiente lingüístico de crianças normais e deficientes mentais: uma análise funcional descritiva [dissertação]. São Carlos (SP): Universidade Federal de São Carlos; 1985.

12. Mayrink MLT. Um estudo do período inicial da aquisição do Português [dissertação]. Campinas (SP): Universidade Estadual de Campinas; 1975.

13. Klin A. Asperger syndrome: an update. Revista Brasileira de Psiquiatria. 2003;2:103-9. 